\title{
Acupuntura, electroacupuntura, moxibustión y técnicas relacionadas en el tratamiento del dolor
}

\author{
R. Cobos Romana \\ Clínica del Dolor del Hospital Universitario Virgen del Rocío, Sevilla. \\ Máster de Acupuntura Médica de la Universidad Pablo de Olavide de Sevilla
}

R. Cobos Romana. Acupuntura, electroacupuntura, moxibustión y técnicas relacionadas en el tratamiento del dolor. Rev Soc Esp Dolor 2013; 20(5): 263-277.

\begin{abstract}
Acupuncture, a major component in Chinese medicine, has a history of well over two thousand years and is effective to maintain good health and to treat various diseases, especially pain. According to classic acupuncture theory, there is a network of meridian channels inside the human body with acupoints on the skin and deeper tissues. Needling at the acupoints modulates the physiology of the body through the meridian channel network. The anatomical structures and physiological functions of the Chinese medicine acupoints, meridian channels and acupuncture have not been shown to have equivalents in modern biomedical science, but modern neuroscience and clinical trials show a high therapeutic potential in the treatment of chronic pain.
\end{abstract}

Key words: Chronic pain. Acupuncture points. Electroacupuncture.

\section{RESUMEN}

La acupuntura, un componente fundamental en la medicina china, tiene una historia de más de dos mil años, siendo desde entonces útil para mantener una buena salud y para el tratamiento de diversas enfermedades, especialmente el dolor. Según la teoría de la acupuntura clásica, existe una red de ca-

Recibido: 06-06-13.

Aceptado: 08-08-13. nales (los meridianos) en el cuerpo humano con puntos de acupuntura, situados sobre la piel y los tejidos más profundos. La punción en los puntos de acupuntura modula la fisiología del cuerpo a través de esa red de canales o meridianos. Las estructuras anatómicas y las funciones fisiológicas de los puntos de acupuntura, según la medicina china y la acupuntura tradicional, a través de la teoría de los meridianos o canales no han demostrado equivalentes en la ciencia biomédica moderna, pero la neurociencia moderna y los ensayos clínicos muestran un alto potencial terapéutico en el tratamiento del dolor crónico.

Palabras clave: Dolor crónico. Acupuntura. Puntos. Electroacupuntura.

\section{INTRODUCCIÓN}

Los métodos que habitualmente se emplean bajo el término "acupuntura" son múltiples y podemos encontrarlos descritos como:

- Acupuntura: empleo de agujas metálicas sobre puntos especiales de la piel.

- Terapia de puntos gatillo: infiltración muy superficial de puntos reactivos de la piel.

- Electroacupuntura: aplicación de corrientes eléctricas especiales sobre agujas de acupuntura.

- Auriculoterapia: estimulación de puntos reflejo del pabellón auricular.

- PENS: electroestimulación sobre agujas percutáneas, no insertadas en puntos de acupuntura.

- Moxibustión: calentamiento de los puntos de acupuntura por medio de la hierba artemisa china.

Se trata de un procedimiento de raíces milenarias, que deriva de la medicina tradicional china. Cronológicamente, 
la medicina tradicional china (MTC) sigue el discurrir de la evolución del ser humano. El carácter chino más antiguo para describir la técnica de la acupuntura es "bambú sobre afilado", 竹子, lo cual indica que la técnica es anterior al desarrollo del Neolítico. Coincidiendo con la etapa de la piedra pulida, aparece el carácter "Pien Tchenn" o punzón de piedra, 者別針, precursor de las agujas de metal, y que fue empleado pasada la frontera del primer centenario tras el nacimiento de Cristo. Sus principios teóricos están expuestos en un texto clásico, el NeijingSuwenLingshu (también conocido como Canon del Emperador Amari1lo), de fecha anterior a nuestra era (muy probablemente del siglo IV al III a.C., y considerado el libro de medicina más antiguo de la humanidad. A partir del desarrollo de los metales aparecen las primeras agujas de metal, 針刺 (1). Por lo tanto, la acupuntura tradicional china recibe el nombre en chino de 针炎Zhēnjiǔ (que significa aguja de metal y fuego), y engloba no solo la técnica de inserción de agujas metálicas, sino que hace referencia a la llamada moxibustión, o calentamiento de los puntos acupunturales, la cual generalmente se lleva a efecto con la planta denominada Artemisia sinensis (una planta similar al ajenjo), que, tras ser desecada y triturada, se emplea a modo de cigarros, a los que se prende fuego. A Europa llegan los primeros conocimientos de la acupuntura a través de la Ruta de la Seda, y muchos de sus procedimientos impregnan a la medicina árabe y medieval. En el siglo XVII, los jesuitas franceses y suizos (el padre Hervieu, y Du Halde, entre otros) publican los primeros textos en lengua occidental referentes a la acupuntura. En el siglo XIX, cirujanos como Cloquet manejan agujas metálicas en la piel, aunque con escaso conocimiento, cayendo en desuso. La primera visita de Nixon a China incita a médicos occidentales a ir a ese país para conocer la aplicación de la técnica. Hoy en día la OMS promueve el desarrollo de la acupuntura, tanto a nivel práctico, como de investigación.

Los fundamentos de la acupuntura tradicional están basados en una paleomedicina, que se ha mantenido a lo largo de siglos, por la constancia de sus efectos. Las teorías de la medicina china son anteriores a la existencia del método científico y, por lo tanto, sus métodos proceden de la observación y son empíricos. Según estas teorías, el elemento principal de nuestra actividad física es el llamado Qi (energía), un elemento no visible, próximo a nuestro sentido occidental e hipocrático de "fuerza vital".

\section{BASES TEÓRICAS DE LA ACUPUNTURA TRADI- CIONAL CHINA}

Según la medicina tradicional china, la actividad vital está soportada por un "soplo" o energía llamado en chino Qi. El Qi recorre todo el organismo a través de unos "canales" que, como no son visibles, se denominan también "meridianos". Las agujas metálicas se insertan en puntos especiales de la piel, que corresponden a los llamados canales o meridianos, por donde circula sangre y energía. Las teorías antiguas hacen referencia a los vasos y a los nervios (1). Las teorías clásicas van dando paso a nuevos hallazgos a la luz de la moderna neurociencia.

\section{Canales o meridianos}

Existen 12 canales principales. Son en número de 12 y bilaterales. Se definen en función de la dialéctica Yin Yang: 3 canales Yin de la mano, 3 canales Yin del pie, 3 canales Yang de la mano y 3 canales Yang del pie. Los canales principales presentan un trayecto superficial y un trayecto profundo (Fig. 1). Hay 3 canales Yin de la mano que salen de un órgano (tórax o abdomen) y se dirigen a la mano: Shou Taiyin (pulmón), Shou Shaoyin (corazón) y Shou Jueyin (pericardio); 3 canales Yang de la mano que parten de la mano y penetran en los órganos y ascienden a la cabeza y son: Shou Tai Yang (intestino delgado) ID, Shou Shao Yang (Sanjiao) SJ y Shou Yang Ming (intestino grueso) IG; 3 canales Yang del pie que salen de la cabeza y se dirigen al pie: Zu Tai Yang (vejiga) V, Zu Shao Yang (vesícula biliar)VB y Zu Yang Ming (estómago) E; y hay 3 canales $\mathrm{Zu}$ Yin que salen del pie y penetran en el tórax o abdomen: Tai Yin (bazo) B , Zu Jue Yin (hígado) H y Zu Shao Yin (riñón) R (Fig. 2).

Los canales y sus colaterales presentan manifestaciones clínicas que sirven de orientación a la terapéutica, y modifican los criterios de aplicación sobre los puntos. La topografía canalar es imprescindible a la hora de aplicar el criterio de tratamiento, de tal forma que las proyecciones del dolor, la presencia de nodulaciones dolorosas, zonas hiperálgicas, e incluso la presencia de telangiectasias, etc. son analizadas de forma sistemática para decidir los puntos del tratamiento.

Se considera que la estructura de los canales está en relación a cómo penetran las fibras a nivel del Tracto de Lissauer, en el asta posterior medular, donde se agrupan las fibras sensibles a la acupuntura, para provocar sensaciones de trayectos lineares a nivel de zonas de la piel.

\section{Puntos}

Los puntos de acupuntura descritos son más de mil, ya que incluyen los correspondientes a los canales, y también los llamados "extraordinarios" o "extracanalares", la mayoría de ellos descubiertos más recientemente. El principio básico de la elección de los puntos se fundamenta en la teoría clásica china de buscar el reequilibrio de la circulación de los canales, causa de la enfermedad, por estimulación de los citados puntos. Modernamente estas teorías 


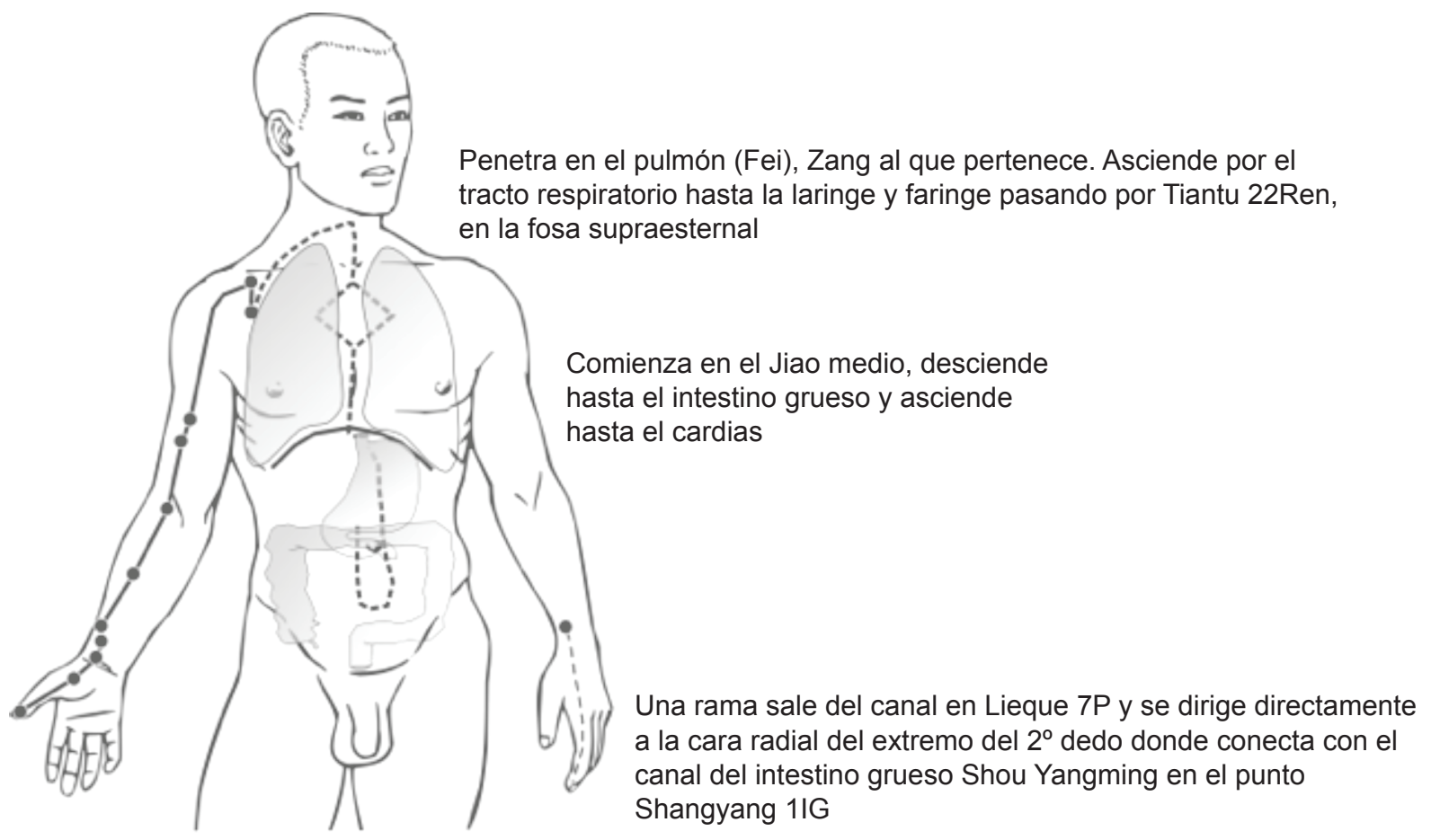

Fig. 1. Canal de pulmón.
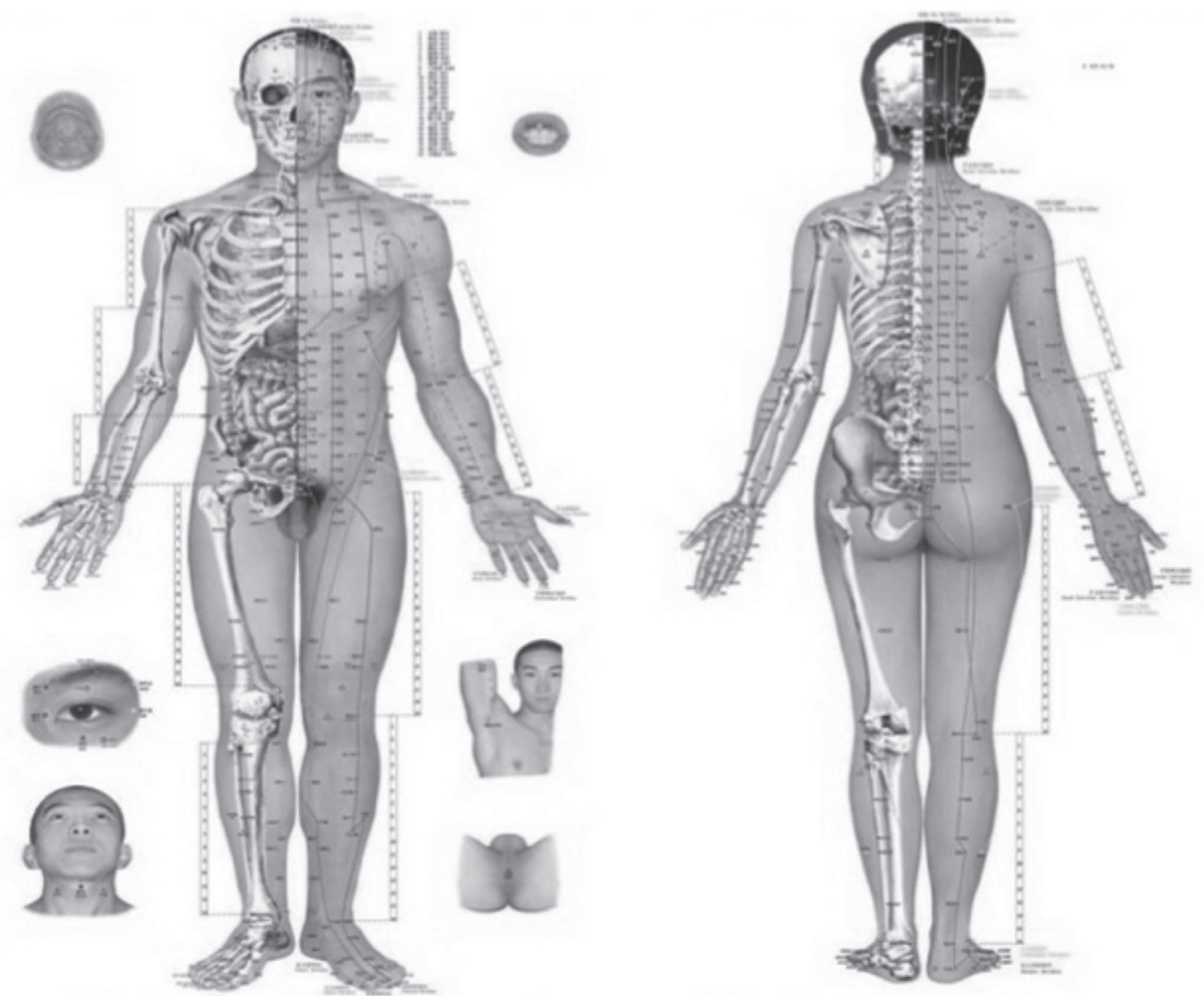

Fig. 2. Canales o meridianos. 
han sido puestas en evidencia por estudios científicos, que han demostrado que el efecto principal de la puntura se produce por estímulo sobre los puntos acupunturales, con carácter específico dado que se encuentran en el trayecto de los principales nervios del cuerpo.

Si un punto de acupuntura envía su información a través de nervios, la estimulación retrógrada de las fibras nerviosas debería posibilitar identificarlos en la superficie de la piel. Este fue la aproximación de Li et al. (2). Según estos investigadores, la distribución de las terminaciones nerviosas de fibras $\mathrm{A} \alpha, \mathrm{A} \beta$ y $\mathrm{A} \delta$ y de las fibras $\mathrm{C}$ sigue un patrón que se asemeja a los canales de acupuntura y se concentra en determinadas zonas que se solapan con la posición de puntos.

Dado que el objetivo de la puntura es conseguir un estímulo nervioso, el enclave del estímulo es el punto acupuntural, cuya estructura tisular no es específica, aunque posee un comportamiento individualizable desde un punto de vista bioeléctrico. De una parte, la piel del punto de acupuntura tiene menos resistencia eléctrica que la circundante (de aquí que se detecte por medio de aparatos eléctricos llamados puntómetros) (Fig. 3), y por otro lado, estudios histológicos llevados a cabo sobre puntos de acupuntura en animales demuestran que hay un mayor acúmulo de receptores nerviosos que las áreas circundantes. Por lo tanto, los puntos de acupuntura tienen comportamientos bioeléctricos específicos. (En sujetos diferentes, se repiten las localizaciones de las zonas de baja resistencia a la piel. La resistencia de la piel baja de valores de $3 \mathrm{M} \Omega$ hasta 10 $\mathrm{K} \Omega$ en el centro del punto. El tamaño del punto determinado por la región de baja resistencia es de 1,5 $\pm 0,5 \mathrm{~mm}$.

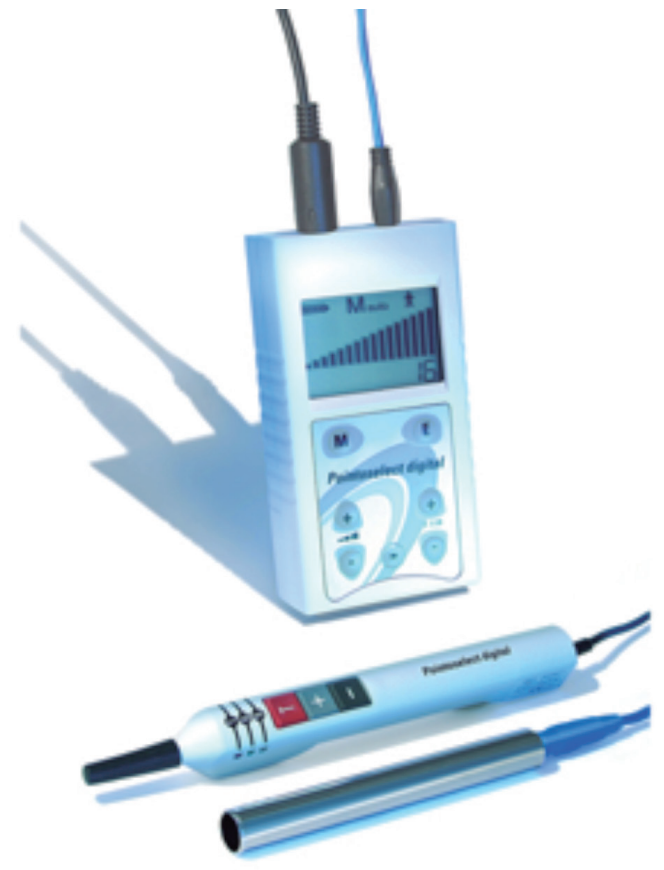

Fig. 3. Detector de puntos de acupuntura.
El valor del potencial eléctrico en estos puntos es diferente al resto de la piel.) (4)

También sabemos que la estructura de los puntos de acupuntura obedece a enclaves de tejido conectivo.

\section{MÉTODO DE LA ACUPUNTURA Y MOXIBUSTIÓN}

\section{Agujas}

La acupuntura emplea agujas metálicas, muy finas y pulidas, de diferentes longitudes y calibres dependiendo de la zona que haya que punturar. Son estériles y desechables. Las medidas varían desde media pulgada, hasta 8 y 10 pulgadas. Lo normal es manejar agujas de entre 1 a 3 pulgadas (Fig. 4).

En una sesión normal, se suelen emplear de 10 a 12 agujas. Tras la inserción, que es prácticamente indolora, se procede a la manipulación acupuntural, que básicamente son movimientos de vaivén y rotación, hasta que los tejidos impiden seguir rotando. Estos movimientos buscan provocar la llamada "sensación acupuntural", también llamada Deqi. Tras la obtención de esta sensación, se realizan maniobras repetidas sobre las agujas (Figs. 5-7) o bien se estimulan eléctricamente o se calientan con la moxibustión.

Una sesión no supera por lo general los 40 minutos, y de promedio basta con media hora. Hoy sabemos que estimulaciones muy repetidas y mantenidas en el tiempo, de más de una hora, pueden desencadenar reacciones contrarias a las buscadas (hiperalgesia).
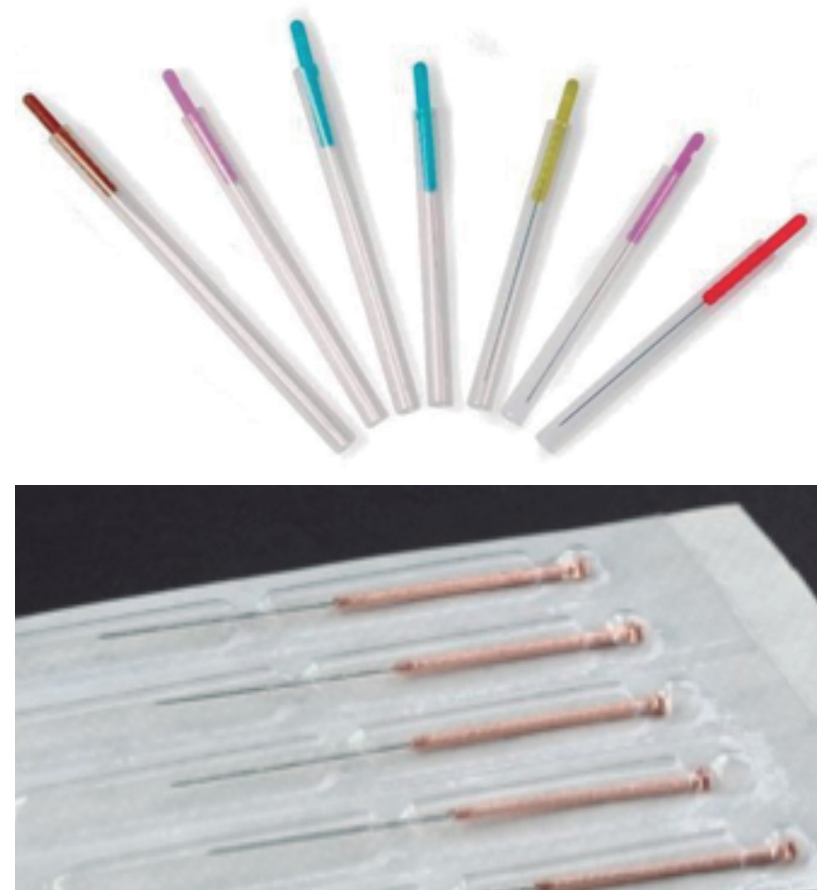

Fig. 4. Agujas de acupuntura. 


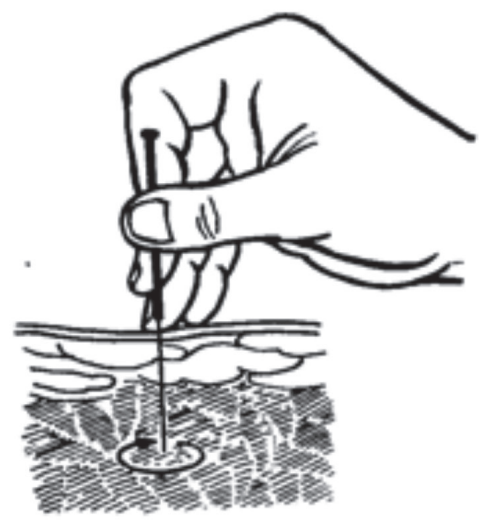

Fig. 5. Manipulación de las agujas.

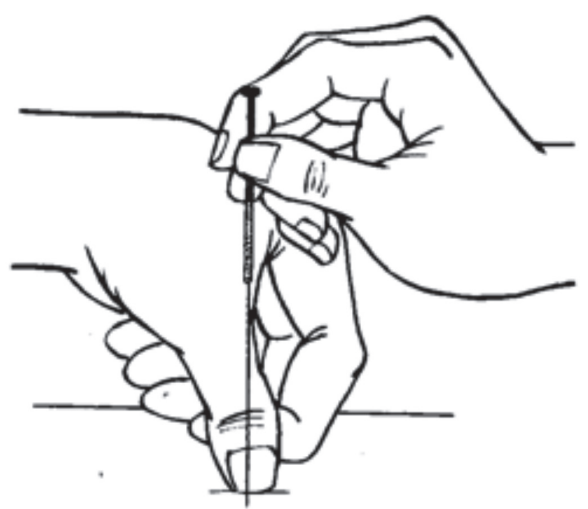

Fig. 6. Técnicas de inserción.

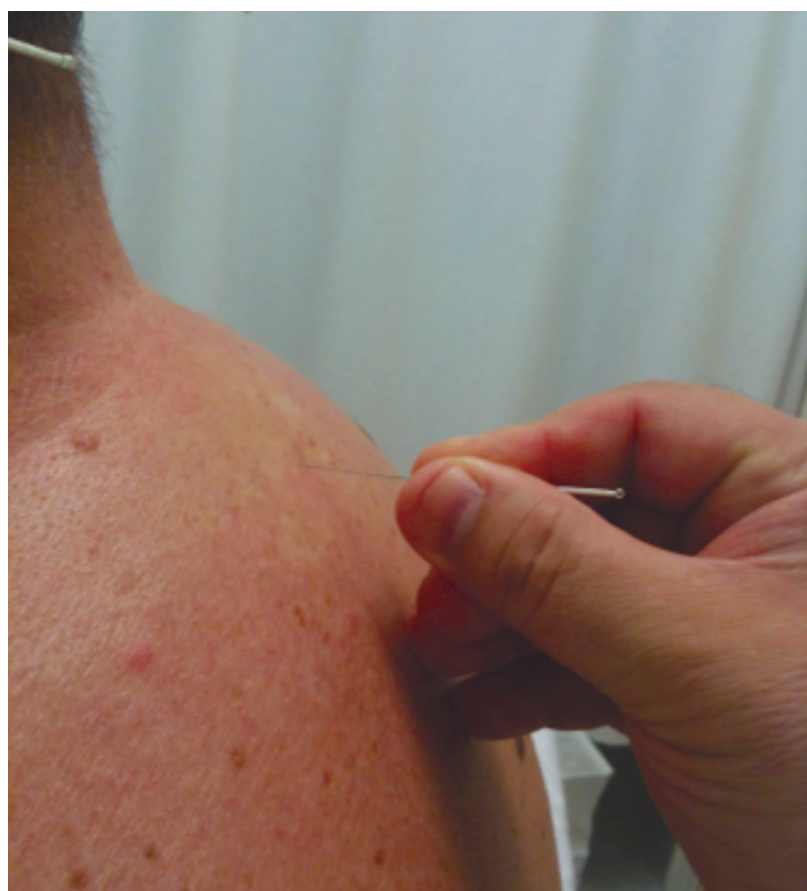

Fig. 7. Inserción de las agujas.
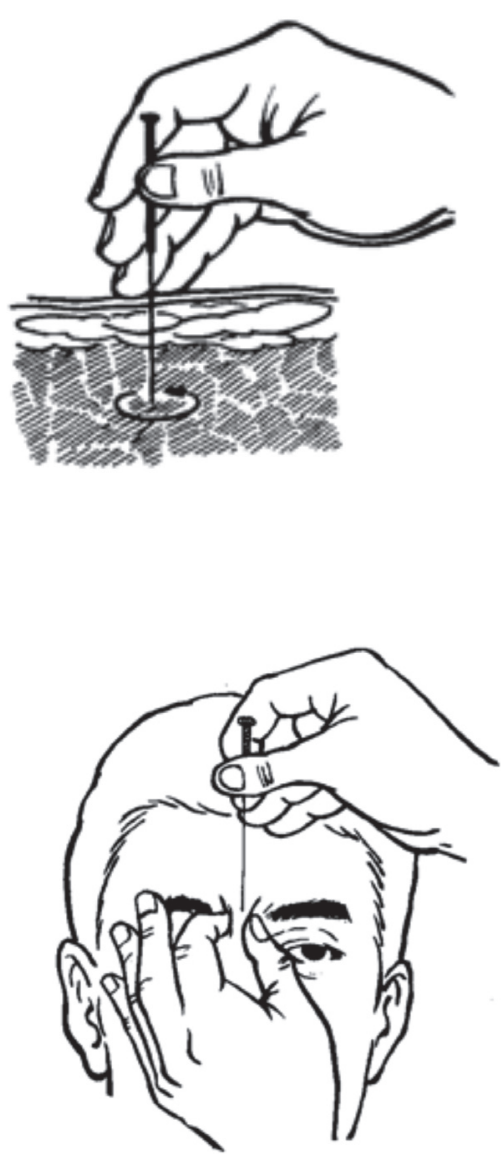

\section{Moxas}

La moxibustión consiste en aplicar calor a los puntos de acupuntura. En algunos casos se cauteriza el punto de acupuntura pero en la mayoría de las ocasiones solo se aplica calor. El método de la moxibustión permite activar los receptores térmicos de la piel, y de esta forma provocar estímulos que compiten con los sistemas de modulación del dolor a nivel de asta posterior medular, y controlar procesos de dolor, sobre todo osteoarticular (3). Para calentar los puntos de acupuntura, se pueden emplear cigarros de polvo de la planta Artemisia sinensis (ajenjo) (Fig. 8), conos de moxa (Fig. 9), y otros sistemas de aplicación indirecta de la moxa con intermedio de plantas. El estímulo de la moxibustión puede alcanzar diferentes niveles a nivel cutáneo y ejercer diferentes efectos según la capa afectada. La moxibustión a temperatura de $47^{\circ}-48^{\circ} \mathrm{C}$ afecta a receptores polimodales de fibras $\mathrm{A} \delta$ y $\mathrm{C}$, que permiten dispersar el calor y bajar la fiebre. Este efecto no se presenta a $40^{\circ} \mathrm{C}$. A nivel central aparece que se activa la región preóptica del hipotálamo anterior. Parece ser que el efecto de la aplicación de la moxibustión reside en la radiación emitida 
de forma selectiva por la combustión de la artemisa (7). Importante: hay que calcular los posibles efectos indeseables de la aplicación de la moxibustión, sobre todo en áreas muy sensibles como cara y dorso, para evitar quemaduras y cicatrices.

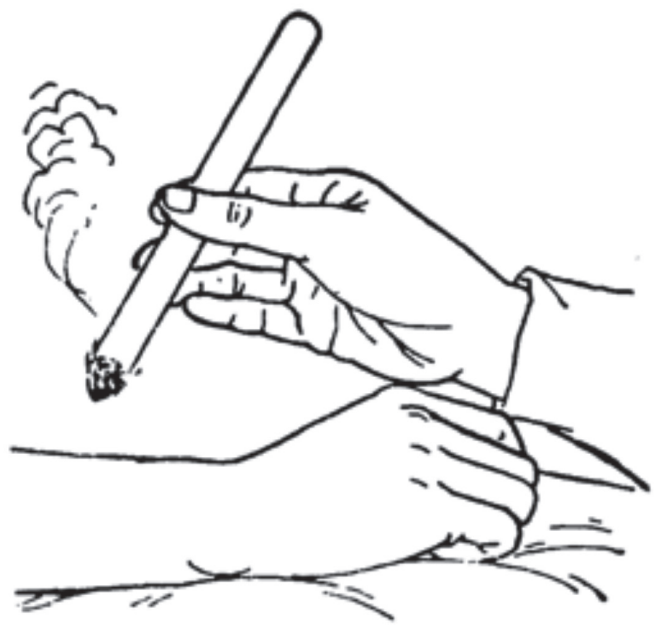

Fig. 8. Técnica de moxibustión. Cigarros de moxa.

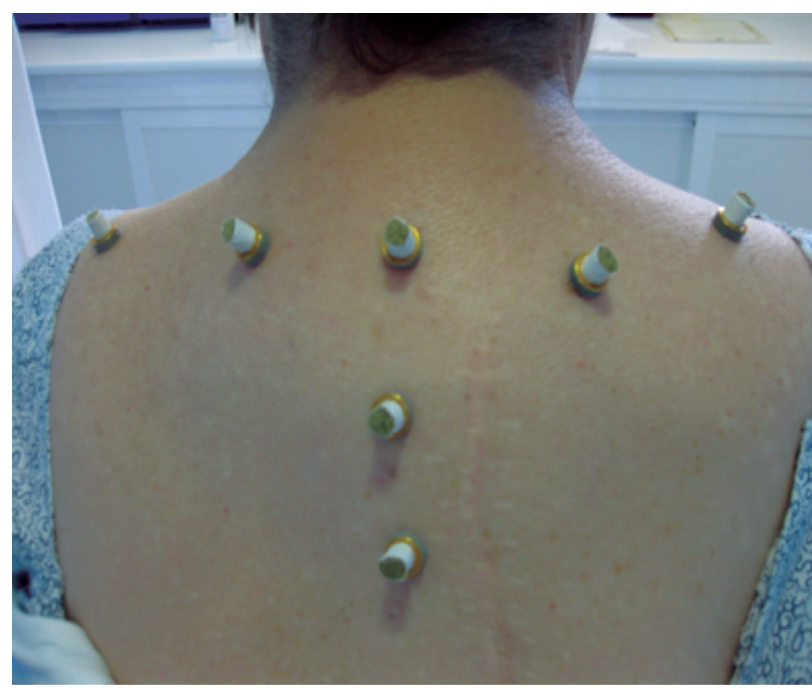

Fig. 9. Conos de moxa.

\section{Electroacupuntura}

La introducción de nueva tecnología a la acupuntura ha supuesto un gran cambio en los métodos. La irrupción de aparatos de electroacupuntura en los años cuarenta no ha cesado en su avance. Los equipos de electroacupuntura emplean corrientes cuadradas de baja frecuencia, que se mueven en los rangos de 2 a $100 \mathrm{~Hz}$ (Fig. 10).

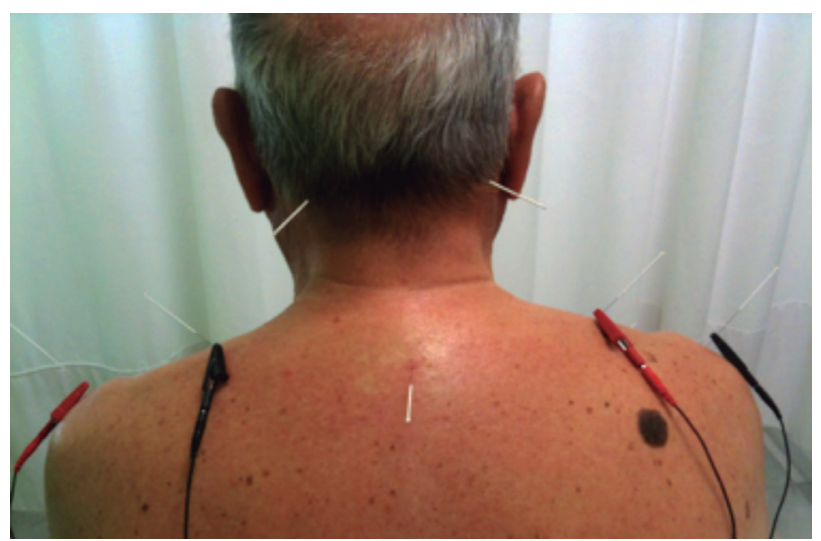

Fig. 10. Electroacupuntura para una cervicalgia.

La investigación sobre los mecanismos de acción de la analgesia acupuntural por electroacupuntura ha permitido no solo fundamentar la técnica, sino que además ha desarrollado importantes avances en la terapia acupuntural.

\section{MECANISMOS DE ACCIÓN DE LAACUPUNTURA EN EL TRATAMIENTO DEL DOLOR}

Son muchos los trabajos que demuestra que la analgesia por acupuntura se produce y reproduce como modelo experimental en animales. Por lo tanto, la analgesia acupuntural tiene una fundamentación fisiológica. Diferentes autores desde 1970 hasta hoy han aclarado los mecanismos de la analgesia por acupuntura. Las primeras consideraciones respecto a los efectos analgésicos de la acupuntura hacen suponer que esta actúa por múltiples mecanismos y a diferentes niveles (Tabla I).

TABLA I. MECANISMOS DE ACCIÓN DE LA ACUPUNTURA

\begin{tabular}{lll}
\hline \multicolumn{1}{c}{ Nivel } & \multicolumn{1}{c}{ Mediadores } & \multicolumn{1}{c}{ Mecanismo de acción } \\
\hline \multirow{2}{*}{ Local } & Adenosina & Bloqueo de la señal nociceptiva local \\
& Mecanotransducción & \\
Segmentario & Factores angiogénicos y neurotróficos & Regeneración tisular \\
Heterosegmentario & Opiodes endógenos, dinorfinas & Bloqueo del asta posterior medular \\
Sistémico & Receptores opiáceos & Modulación del dolor en corteza, áreas \\
& Cortisol-ACTH & somatosensoriales y límbico (SGP)
\end{tabular}




\section{Mecanotransducción y analgesia acupuntural}

Recientemente se están planteando otros mecanismos de acción, que se han evidenciado por investigación básica, por un lado la correlación entre la mecanotransducción de la manipulación mecánica del punto, y por otro, acciones locales con efectos analgésicos locales. En el primer caso tiene mucha importancia porque explica el fenómeno de latencia del efecto acupuntural, y por otro, la propagación del efecto, por transmisión de señales mecánicas y no por vía exclusivamente nerviosa.

Así se observó que la acupuntura aplicada en ratones para que genere sus acciones anti-nociceptivas requiere la expresión del receptor de adenosina A1 (8). La inyección directa de un agonista del receptor de adenosina A1 reproduce el efecto analgésico de la acupuntura. También se ha demostrado que la inhibición de las enzimas implicadas en la degradación de adenosina potenció el aumento de la acupuntura, así como su efecto anti-nociceptivo. Estas observaciones indican que la adenosina media en los efectos analgésicos de la acupuntura y que interfiriendo en la degradación del metabolismo de la adenosina se puede prolongar el beneficio clínico de la acupuntura.

La acupuntura desencadena señales inducidas por la purina y provoca remodelación del citoesqueleto de fibroblastos que contrarresta la fibrosis (baja TGF- $\beta$ ). Además, la adenosina tiene varias acciones antiinflamatorias que pueden contribuir a la reducción a largo plazo de dolor persistente por efecto analgésico de la acupuntura (9).

Los experimentos realizados en los diez últimos años, en diferentes laboratorios de universidades de los Estados Unidos, muestran una correlación directa entre manipulación de las agujas y efectos de transmisión de señales, que a la larga generan modulación e inhibición del dolor.
Las investigaciones de la profesora Langevin (10) muestran cómo existe un modelo de mecanotransducción descrito en términos de equivalencia entre fenómenos descritos por la antigua acupuntura, y efectos sobre el tejido intersticial y conjuntivo (Tabla II).

\section{MECANISMOS NEUROBIOLÓGICOS DE LA ANALGESIA ACUPUNTURAL}

\section{Nivel segmentario medular}

La acupuntura actúa poniendo en marcha los mecanismos de acción de la "puerta de entrada" a nivel de la sinapsis entre la neurona periférica y la de transmisión central. Esto se ha comprobado por varios estudios, como la correspondencia entre los dermatomos en los que se colocan las agujas y los mielómeros donde se ejerce el efecto analgésico. También se ha constado la inhibición del reflejo postináptico del axón y la aparición de un potencial negativo de raíz posterior, por acción de la acupuntura. La mayor parte de las acciones de la analgesia por acupuntura son producidas a nivel presináptico espinal, sin embargo, hay otras estructuras superiores implicadas. Diferentes autores afirman que la vía por la que caminan los impulsos inhibidores ejercidos por la analgesia por acupuntura se localizan en el cordón lateral, pars ventralis, del lado opuesto de la estimulación. Por ello, la sección de estos cordones por la parte lateral no inhibe la acción de la acupuntura. La anestesia por medio de anestésicos locales de un punto de acupuntura inhibe sus efectos. Nosotros pudimos localizar en 1988 las estructuras medulares, que estaban implicadas en dicha analgesia, al aplicar marcadores inmunocitoquímicos para la metencefalina (MetENK), en gatos sometidos a electroacupuntura de baja frecuencia (11).

TABLA II. RESUMEN DEL MODELO DE EFECTOS FISIOLÓGICOS EN ACUPUNTURA Y TEJIDO CONJUNTIVO

Conceptos de la medicina china clásica

Canales de acupuntura

Puntos acupunturales

Qi canalar

Bloqueo de $Q i$

Atrapamiento de la aguja

Sensación de Qi

Propagación de $Q i$

Restauración del flujo de Qi
Propuesta de equivalencias anatómico-fisiológicas

Planos de tejido conjuntivo

Convergencia de planos de tejido conjuntivo

Señalización bioeléctrica/bioquímica en el tejido conjuntivo

Alteración de la matriz del tejido conjuntivo que conduce a una alteración de la transducción de señales

Enrollamiento del tejido y/o contracción de los fibroblastos alrededor de la aguja

Estimulación de los mecanorreceptores sensoriales del tejido conjuntivo

Onda de contracción del tejido conjuntivo y estimulación de los receptores sensoriales a lo largo del plano de tejido conjuntivo

Activación celular/expresión génica que conduce a restaurar la composición de la matriz del tejido conjuntivo y transducción de señales 


\section{Acción a nivel diencefálico}

La lesión de zonas específicas del diencéfalo revierte la analgesia acupuntural, concretamente la zona del raphe magnus y las vías descendentes serotonérgicas, que son muy importantes en esta acción. La aplicación de sustancias que inhiben la síntesis de serotonina, como la dicloroparafenilalanina (DCPFAL), muestran reducciones notables de la analgesia de la acupuntura. De igual forma, la naloxona revierte los efectos de la analgesia acupuntural, lo que demostró hace años su mecanismo opiáceo-hormonal. El núcleo caudado también está en relación con los efectos de la acupuntura.

\section{Acción a nivel talámico}

La acupuntura inhibe de manera específica neuronas que responden a estímulos dolorosos, localizándose en núcleos ventromediales.

\section{Acción a nivel cortical}

Aun de manera imprecisa, se considera que la acupuntura es capaz de actuar sobre la corteza motora y tiene acción sobre los estados emocionales, posiblemente por acción sobre el GABA. Las técnicas de resonancia magnética funcional en los últimos años han aportado datos muy esclarecedores de las acciones corticales específicas de la acupuntura (12).

Se ha comprobado que la estimulación de parejas de puntos de acupuntura activa regiones:
- 36E/6B (puntos de la esfera gastrointestinal) activaron: área somatosensorial $2^{\mathrm{a}}$, ínsula, tálamo ventral, área 40 Brodman, lóbulo temporal, putamen, cerebelo y desactivaron la amígdala (áreas relacionadas con la modulación de la actividad visceral).

- 34VB/57V (funcionamiento de músculos y tendones) activaron: tálamo dorsal, e inhibieron: área motora primaria y corteza promotora (involucrado en funciones motoras) (Fig. 11).

\section{Papel de la frecuencia en las acciones analgésicas}

La neurociencia actual ha permitido establecer la bioquímica de la analgesia por acupuntura, que básicamente es una acción neuromoduladora.

Resumen: Existen dos mecanismos de acción neuromoduladora de la acupuntura:

1. A nivel tronco y diencefálico, con frecuencias bajas (2 a $15 \mathrm{~Hz}$ ), y alta intensidad del estímulo. Lo que depara una analgesia difusa y de larga duración. Fenómenos de neuromodulación de efectos acumulativos y a largo plazo.

2. A nivel metamérico, por cierre de la puerta de entrada medular, segmentario y de corta duración, por estimulación de baja intensidad y de alta frecuencia $(120 \mathrm{~Hz})$.

A fecha de hoy se sabe que hay dos modos de acción de la analgesia acupuntural: una de instauración rápida y breve duración, que se consigue con estímulos de alta frecuencia ( $100 \mathrm{~Hz}$ o más), y otra de instauración lenta y larga duración que se produce a $2 \mathrm{~Hz}$. Una sería útil para el dolor agudo y la otra, para el crónico.

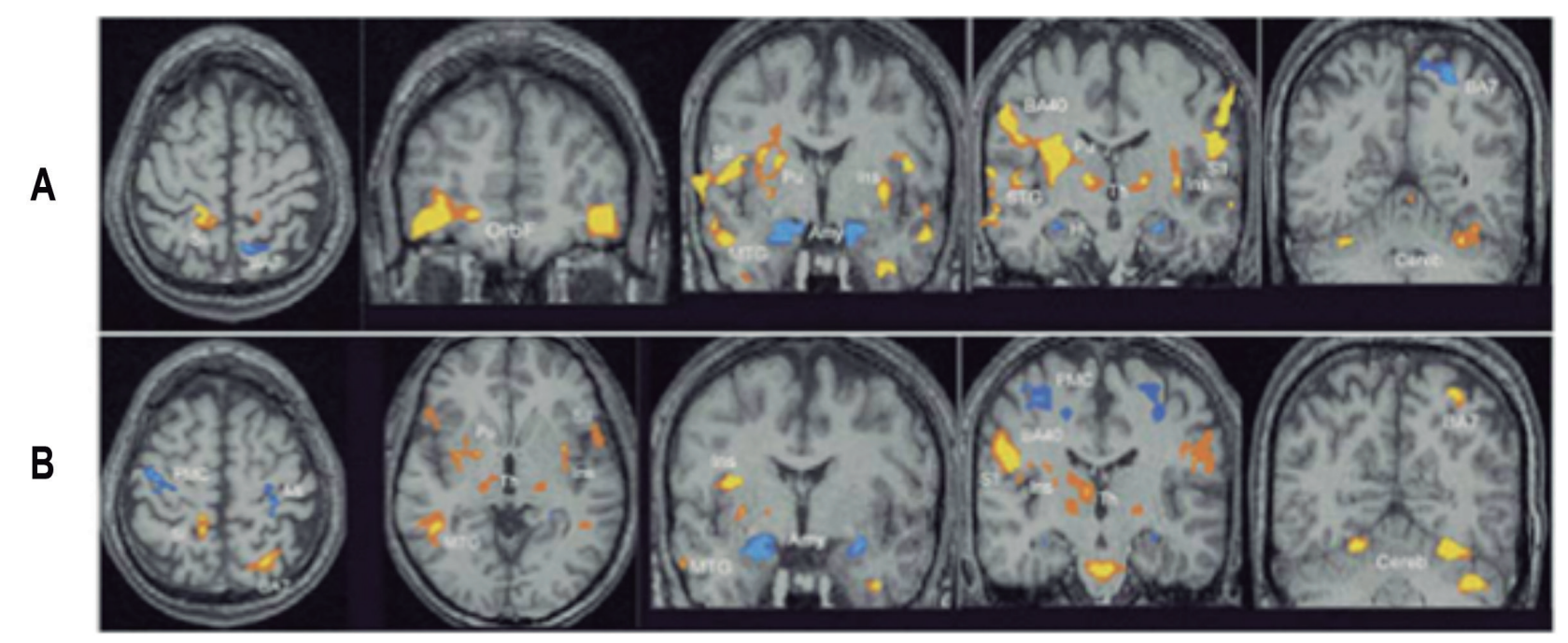

Fig. 11. A. Activación de áreas por estimulación de 36E/6B. B. Activación cerebral por estimulación de 34VB/57V (tomado de Zhang, W.T., Jin Z., et al. [2004]. Evidence from brain imaging with fMRI supporting functional specificity of acupoints in humans Neurosci Lett 354[1]:50-3) (12). 
Un hallazgo importante observado ha sido que la capacidad de la electroacupuntura de acelerar la liberación de opioides endógenos en SNC depende, entre otras cosas, de la frecuencia utilizada (13). La electroacupuntura a 2 $\mathrm{Hz}$ aumenta la liberación de $ß$-endorfina en el cerebro y de encefalina en todo el SNC, mientras que a $100 \mathrm{~Hz}$ la electroacupuntura incrementa la liberación de dinorfina en la médula espinal. Este hallazgo, descrito originalmente en ratas, se ha verificado en humanos. En recientes estudios, se han descrito las vías nerviosas de conducción a $2 \mathrm{~Hz}$ y $100 \mathrm{~Hz}$ (N. Arcuatus, N. Parabraquial y Sustancia Gris Periacueductal) (14).

Así, cambiando el dial del estimulador, es posible controlar aisladamente la liberación de tres tipos de péptidos opioides. Para acelerar la liberación de los tres tipos de péptidos opioides, al mismo tiempo, se puede usar la onda "densa- dispersa", es decir, $2 \mathrm{~Hz}$ durante 3 segundos seguido de $100 \mathrm{~Hz}$ durante 3 segundos y cambia de un lado a otro automáticamente (15). Esta forma de onda produce la liberación simultánea de los tres tipos de péptidos opioides. La interacción sinérgica de los péptidos opioides puede producir un efecto más potente (16) (Fig. 12).

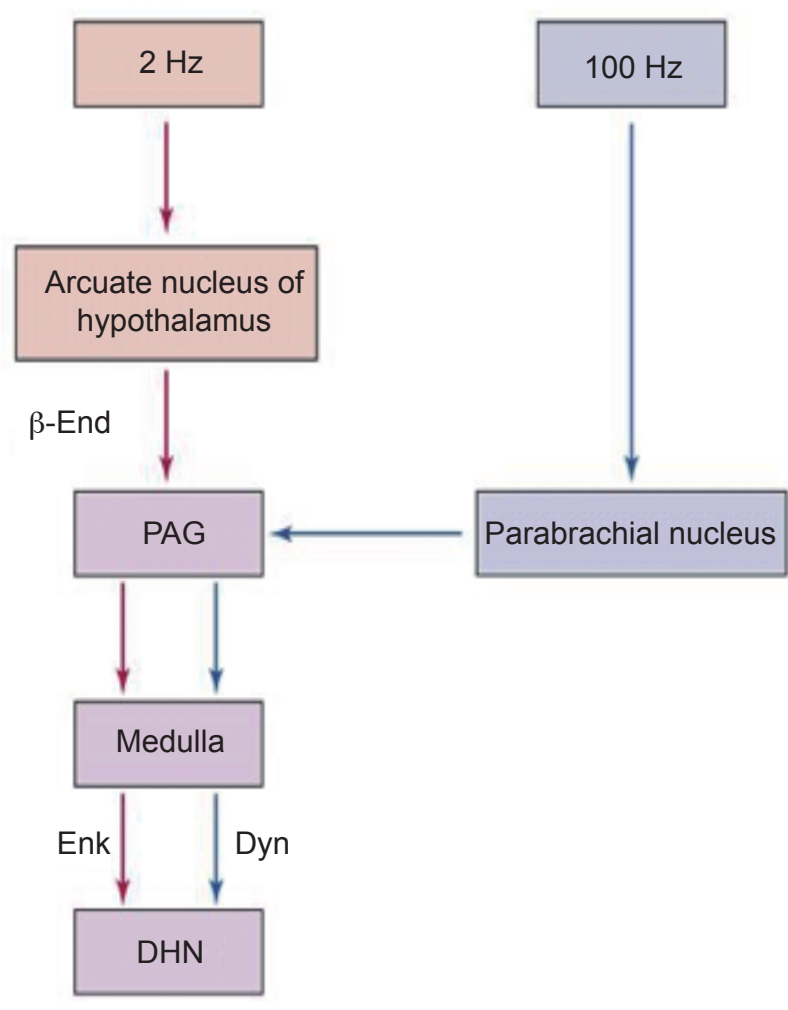

Hoy, según los resultados de estas investigaciones, podemos plantear el empleo sistemático de la EEA para liberar los péptido opiáceos de forma controlada.

\section{Bases bioquímicas de la variación individual}

Parece que existe una base genética determinante de la repuesta a la analgesia por acupuntura. Dos tercios de los animales son "alto-respondedores" (incrementan el umbral doloroso más del $60 \%$ ) un tercio son "bajo-respondedores" (el umbral de dolor varía menos del $60 \%$ ) (18).

\section{Mecanismo de los respondedores bajos}

Se ha demostrado que hay animales de experimentación que, frente a la electroacupuntura liberan un nivel bajo de péptidos opioides en el SNC. Liberan un nivel alto de (colecistoquinina) CCK en respuesta al estímulo de la EAA. Existen posibles soluciones, se ha demostrado experimentalmente que una rata "bajo-respondedora" puede conver-

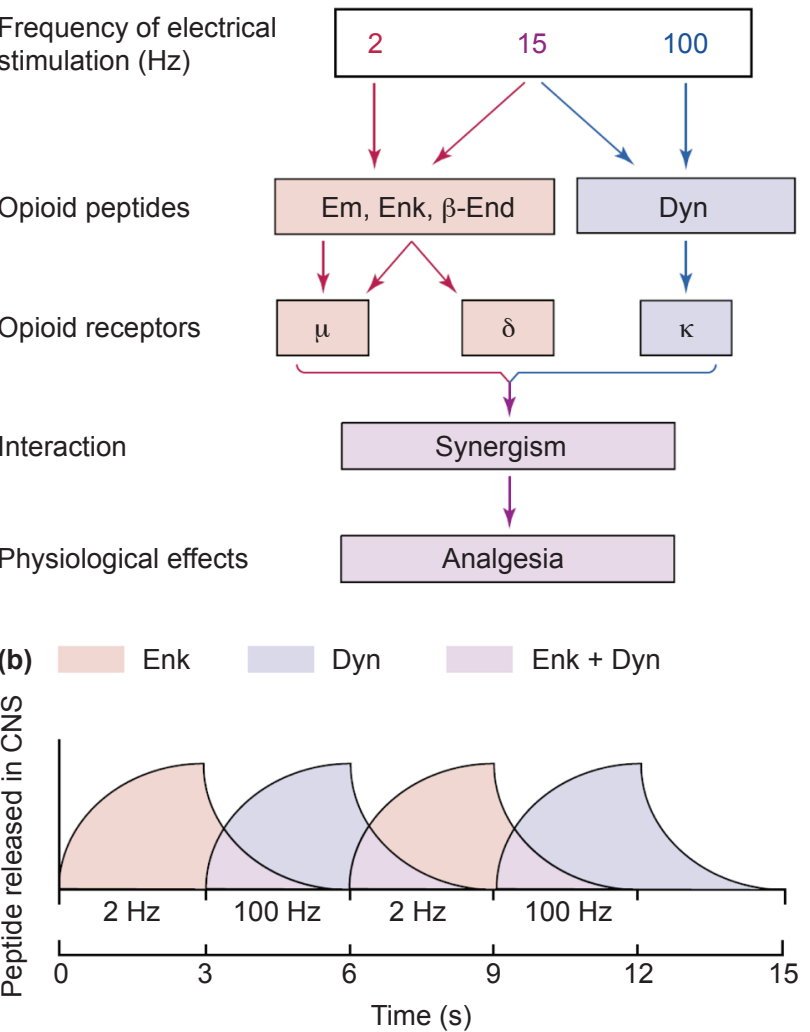

Fig. 12. Efecto de la electroestimulación a diferentes frecuencias (tomado de Han, J. S. [2003]. Acupuncture: Neuropeptide release produced by electrical stimulation of different frequencies. Trends Neuroscience 26[1]:17-22) (17). 
tirse en un "alta-respondedora" si se suprime el gen de expresión de la CCK con la tecnología adecuada. Esto ya se ha hecho con el antagonista de CCK-B, el L-365260 (19).

Esto nos lleva a contemplar la presencia de tolerancia a la electroacupuntura, mediado por un efecto antiopiáceo. Está descrito el efecto antiopiode provocado por la liberación de colecistocinina y orfanina FQ. En los estudios con EAA, la estimulación prolongada con EAA durante varias horas produce una disminución gradual del efecto analgésico, que ha sido denominado "tolerancia a la acupuntura". Simula la tolerancia desarrollada frente a morfina después de su inyección repetida. Esto se debe a que la estimulación prolongada con EAA acelera la producción y liberación del péptido CCK que actúa con efecto antiopioide. Los mecanismos celulares y moleculares del efecto antiopioide de la CCK han sido aclarados. En experimentos con ratas, puede prevenirse o revertirse la tolerancia a la acupuntura mediante la inyección intracerebroventricular (icv) del anticuerpo frente a CCK que impide a la CCK unirse a su receptor (20).

\section{Antiopioides y acupuntura}

Orfanina FQ (OFQ), un péptido clonado recientemente, si se inyecta intracerebrovascularmente, atenúa, con efecto dosis dependiente, tanto la analgesia por morfina como la de la EAA. La inyección icv de anticuerpo ARN comple- mentario al receptor de OFQ, que reduce el número de receptores de OFQ, potencia la analgesia de la EAA de forma importante.

\section{Papel de las monoaminas}

Serotonina, dopamina y noradrenalina están también involucradas en la analgesia por EEA. Así, sabemos que la mayoría de la serotonina (5-HT) existente en el SNC proviene de las neuronas localizadas a lo largo de la línea media del cerebro. Se ha demostrado el papel de la serotonina en la EEA, bloqueando la biosíntesis de 5-HT, destruyendo las neuronas de 5-HT, a través de 5,6-DHT, o bloqueando los receptores de 5-HT con cinanserina se obtiene una marcada reducción de EAA. Las catecolaminas (dopamina [DA] y noradrenalina [NA]) tienen diferentes funciones en varias localizaciones del SNC. Se demostraría en la década de los 80 que antagonizan la EAA en el cerebro y potencian la EAA en la médula espinal (21) (Fig. 13).

\section{CUADROS DE DOLOR SUSCEPTIBLES DE SER TRATADOS CON ACUPUNTURA}

Existen evidencias cada vez más abundantes sobre la eficacia y seguridad de los tratamientos con acupuntura en el dolor crónico.

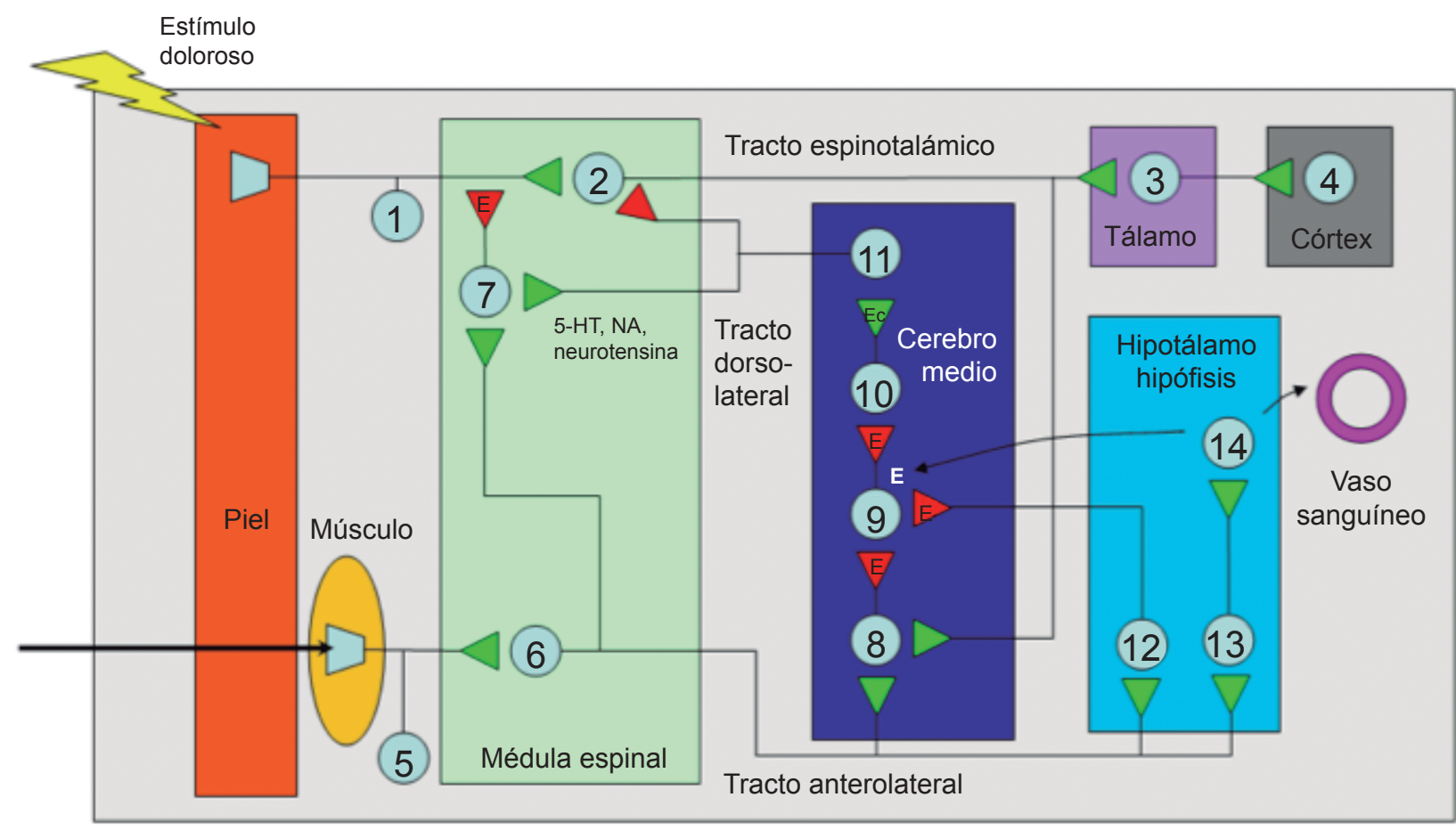

Fig. 13. Esquema de los centros nerviosos y sistemas de neurotransmisores implicados en la analgesia acupuntural (modificado de Stux, G. y Pomeranz, B. Fundamentos de Acupuntura [2004], Ed. Masson [Elsevier]) (21). 
La realización de ensayos controlados ha supuesto un cambio de indicación en los últimos años. Y todo ello, a pesar de las dificultades que plantea la técnica para su enmascaramiento, siguiendo las directrices del sistema doble ciego, ya que la aguja placebo es muy difícil de diseñar, y las actuales están en cuestión. Tampoco parece muy segura la metodología de la llamada sham acupuncture, según la cual se compara el efecto de la acupuntura con punturas fuera de los puntos, o la llamada acupuntura mínima, con punciones superficiales, ya que, como demostró Le Bars (22), existe un mecanismo nociceptivo difuso, que es capaz de generar modificaciones en los neurotransmisores de la vía del dolor.

\section{Gonartrosis}

Son múltiples los ensayos clínicos controlados que muestran una mejora evidente del dolor, y la movilidad (empleando escalas como la WOMAC), que suponen una mejora de los niveles de calidad de vida de los pacientes (23).

En el trabajo británico de Whitehurst et al. (24) se realizó un estudio de coste-efectividad con 352 pacientes diagnosticados de artrosis de rodilla comparando el tratamiento estándar, tabla de ejercicios y consejo médico, con el tratamiento estándar más acupuntura. A pesar del incremento del coste en el brazo que sumaba la acupuntura a los cuidados, la diferencia de los años de vida ajustados por calidad (AVAC) era significativamente superior $(p=0,022)$, con una probabilidad del $77 \%$ de obtener una intervención coste-efectiva, si se asume un valor conservador de 20.000 libras por AVAC en el Reino Unido.

En el trabajo alemán de Reinhold et al. (25) se incluyeron 489 pacientes con artrosis de rodilla y cadera. En ambos grupos se indicó tratamiento convencional, ofrecido por el sistema sanitario nacional alemán, junto con acupuntura inmediata en un grupo y demorada a los 3 meses en el grupo control.

Se realizaron entre 10 y 15 sesiones de acupuntura durante 3 meses. La variable resultante, medida por ratio coste-efectividad incremental (RCEI), fue de $17.845 €$ por AVAC, claramente positiva si se asume el valor máximo de 50.000 € por AVAC en Alemania.

\section{Cervicalgia}

El trabajo alemán de Willich et al. reunía a 3.451 pacientes con dolor cervical crónico y un diseño similar al trabajo previo realizado en la artrosis de rodilla y cadera. El RCEI global fue de $12.469 €$, por lo que la acupuntura se mostraba coste-efectiva en esta patología (26).
Todavía queda camino por recorrer, en la investigación sobre la eficacia y seguridad de la acupuntura en el tratamiento del dolor, pero los avances habidos en los últimos cinco años hacen suponer que el nivel de evidencias disponibles colocará a la acupuntura dentro del arsenal habitual de técnicas de control del dolor tanto en el nivel de la asistencia primaria, como en la hospitalaria.

\section{Lumbalgia}

Los estudios sobre la eficacia y seguridad de los tratamientos con acupuntura en la lumbalgia inespecífica, tanto crónica, como aguda, han demostrado un beneficio importante sobre la evolución natural de la enfermedad.

La mayoría de los estudios muestran un beneficio de la aplicación de la técnica a corto y medio plazo, incluso con beneficios superiores sobre procedimientos estándar de tratamiento. La mayoría de los ensayos controlados han modificado los niveles de evidencia disponibles y eso ha permitido indicaciones nuevas.

Destacan por su importancia los trabajos del Grupo de trabajo GERAC, que desarrolló un ensayo multicéntrico, randomizado, ciego controlado en tres grupos, sobre un total de 1.162 pacientes de entre 18 a 86 años, con la participación de más de 300 médicos acupuntores. Este trabajo demostró que la acupuntura era superior a la aplicación de procedimientos habituales en el tratamiento, con una media de 12,5 sesiones sobre los pacientes tratados, y seguidos durante seis meses (27).

La más reciente revisión sistemática, publicada en Spine en 2008, analiza veintitrés ensayos de los que fueron incluidos clasificados en 5 tipos de comparaciones, de los cuales 6 eran de alta calidad. Hay pruebas moderadas de que la acupuntura es más efectiva que ningún tratamiento, y una fuerte evidencia de que no hubo diferencia significativa entre la acupuntura y la acupuntura simulada, a corto plazo para el alivio del dolor. Este trabajo concluye que hay pruebas sólidas de que la acupuntura puede ser un complemento útil de otras formas de la terapia convencional para la lumbalgia inespecífica. Concluye dicha revisión que la acupuntura versus ningún tratamiento, y como un complemento a la atención convencional, debe ser incluida en las Directrices Europeas para el tratamiento de la lumbalgia crónica (28).

En el estudio clínico aleatorizado y pragmático de Witt et al. se reclutaron 11.630 pacientes con lumbalgia crónica y fueron divididos en tres grupos: 1.549 aleatorizados al grupo de acupuntura, 1.544 al grupo control, y 8.537, que no firmaron el consentimiento de aleatorización, fueron a un tercer grupo con acupuntura. Todos los pacientes recibieron cuidados estándares convencionales. La mejoría de la lumbalgia fue significativa $(\mathrm{p}<0,001)$ en los grupos tratados con acupuntura. El RCEI global fue de 
Rev. Soc. Esp. del Dolor, Vol. 20, N. ${ }^{\text { 5 }}$, Septiembre-Octubre 2013

$10.526 €$ por AVAC, cifra claramente inferior al RCEI de $73.310 €$ por AVAC de una cirugía convencional para estabilizar la espalda (29).

La aplicación del PENS tiene evidencias muy altas de eficacia sobre cuadros de lumbalgia inespecífica con tratamientos cortos e intensos (30). Esta técnica se beneficia de los modelos de neuroestimulación eléctrica tipo TENS, junto al efecto de la estimulación de agujas percutáneas. Los ensayos disponibles ponen de manifiesto la eficacia y seguridad del PENS, en lumbalgias tanto crónicas como agudas, e incluso en las radiculalgias.

Dos situaciones concretas alrededor de la lumbalgia y su tratamiento han demostrado un campo de utilidad concreto, como es el caso de la lumbalgia en ancianos, en los que la coexistencia de otras patologías limita el uso de medidas convencionales de tratamiento, y de otra parte hay estudios que muestran la eficacia y seguridad de la acupuntura en los casos de lumbalgia y dolor pélvico en las embarazadas $(31,32)$.

Por último, se han llevado estudios muy serios sobre el coste de la introducción de estas técnicas comparándolas con las convencionales, y muestran que es muy competitiva, frente a los costes generales de los cuidados convencionales. El NICE (National Institute for Clinical Excellence del Reino Unido) recomienda el empleo de la acupuntura para el tratamiento de la lumbalgia inespecífica (33).

\section{Cefaleas}

Destacan las investigaciones realizadas en Alemania y Reino Unido, que plantean que la acupuntura es tan eficaz como los tratamientos empleados de forma habitual, con una importante reducción de costes respecto al empleo de fármacos y mejora de la pérdida de días de trabajo. La acupuntura aporta beneficios en el tratamiento, con muy escasos o casi nulos efectos secundarios o indeseables. Se evidencia que la acupuntura actúa tan bien como, y a veces mejor que, la terapia habitual en el mismo problema. Hay evidencia adicional de que la acupuntura puede tener menos efectos colaterales que la terapia convencional (34-37). Creemos que estudios de coste-eficacia deberían aclarar su aplicación sistemática sobre la población afecta, sobre todo de migraña y cefalea por tensión. Por último, vemos una indicación interesante en la aplicación de la acupuntura en pacientes con cefalea por abuso de analgésicos, dado que puede controlar el dolor a la vez que retiramos los analgésicos. Guías clínicas como la NICE la han incorporado en el nivel de tratamiento, tanto de cefalea tensional, como en la mixta y migraña (38).

En general los resultados de los metaanálisis muestran una evidencia cada vez mayor de la eficacia y coste-efectividad de la acupuntura en el dolor crónico (39) (Tabla III).
TABLA III. NIVELES DE EVIDENCIA

\begin{tabular}{ll}
\hline \multicolumn{1}{c}{ Patología } & Nivel de evidencia \\
\hline Artrosis (gonartrosis) & $1 \mathrm{a}$ \\
\hline Lumbalgia & $1 \mathrm{a}$ \\
\hline Cervicalgia & $1 \mathrm{a}$ \\
\hline Síndrome dolor miofascial & $1 \mathrm{a}$ \\
\hline Epicondilitis & $1 \mathrm{~b}$ \\
\hline Omalgia & $1 \mathrm{~b}$ \\
\hline Cefalea & $1 \mathrm{a}$ \\
\hline Dismenorrea & $1 \mathrm{c}$ \\
\hline
\end{tabular}

\section{MODOS DE APLICACIÓN DE LA ACUPUNTURA}

Las evidencias disponibles apuntan a una serie de procesos de dolor crónico con una alta incidencia sobre la población. Así podemos hablar de dos modos de aplicación de la acupuntura.

\section{Principal o tratamiento único}

Se elige el tratamiento con acupuntura como primera elección, o se le ofrece como alternativa cuando no se pueden aplicar los procedimientos de analgesia habitual (fármacos) por intolerancia, alergia y/o incompatibilidad por otras patologías concomitantes o sus tratamientos.

\section{Complementaria}

Cuando se aplica el proceso para aumentar la escasa respuesta obtenida por los procedimientos aplicados para eliminar el dolor, o cuando la aplicación de la acupuntura se simultanea con otros tratamientos para el dolor (ejemplo: rehabilitación).

\section{Resumen de indicaciones y contraindicaciones}

Con diferentes niveles de evidencia, muestran beneficio sobre:

- Cervicalgia.

- Dolor de hombro.

- Neuralgias faciales.

- Dismenorrea.

- Fibromialgia.

- Codo de tenis.

- Síndrome de túnel del carpo. 
Es fundamental la aplicación de criterios de inclusión-exclusión para tratamiento con acupuntura.

En 1987, en la memoria de la Clínica del Dolor del Hospital Virgen del Rocío, se establecieron por vez primera estos criterios:

\section{Criterios de aceptación}

- Diagnóstico preciso.

- Exclusión de solución quirúrgica.

- Tratamiento farmacológico excluido por:

- Hipersensibilidad medicamentosa.

- Yatrogenia derivada del uso de AINE o analgésicos.

- Ulcus gastroduodenal activo o sangrante.

- Respuesta a la primera sesión:

- Reducción en un 75\% de la valoración inicial.

- Valoración a la quinta sesión, reducción progresiva hacia 0 de:

- Analgésicos.

- Miorrelajantes.

- Sedantes.

- Ausencia de indicación prioritaria de otras técnicas antálgicas.

- Antecedentes previos de tratamiento eficaz con acupuntura.

- Facilidad de desplazamiento a la unidad.

\section{Criterios de exclusión total}

- Diagnóstico inexistente, incompleto o confuso.

- Indicación quirúrgica clara.

- Ausencia injustificada de tratamiento previo.

- Embarazo (es un criterio relativo, según las técnicas aplicadas).

- Paciente sometido a tratamientos en concomitancia con:

- Antiblásticos.

- Corticoides sistémicos.

- Inmunosupresores.

- Mórficos (debe observarse la posibilidad de efectos sumatorios).

- Enfermedad psiquiátrica grave en actividad.

- Grave deterioro del estado general.

- Hipocoagulación.

- Proceso febril.

- Dermopatía generalizada y grave.

\section{Efectos secundarios, seguridad y niveles de competencias}

La técnica de acupuntura es muy segura, pero no está exenta de posibles daños o iatrogenias (40):

- Neumotórax.

- Perforación de vísceras huecas.
- Hematomas.

- Sangrado.

- Lesión de nervios.

\section{Nivel de competencias}

Cabe preguntarse quién debe aplicar estas técnicas. La aplicación de la técnica de acupuntura cumple con los criterios de un acto médico, por lo tanto, el médico experto en acupuntura debe dirigir el proceso, aun cuando pueden concurrir en él otros profesionales de la salud, sobre todo DUE y fisioterapeutas, quienes, tras haber recibido formación específica, aplican el procedimiento. La Consejería de Salud y la Agencia de Calidad han aprobado el nivel de acreditación del acupuntor/a en el Sistema Andaluz de Salud, que garantiza la idoneidad de quienes apliquen las técnicas, tanto a nivel de Asistencia Primaria como especializada, que permite obtener un reconocimiento, expreso y público, del cumplimiento de los requisitos necesarios para prestar una asistencia de calidad, así como el inicio de una línea de mejora continua por parte del profesional. La elección de las técnicas, así como el número de sesiones, y los cambios del tratamiento, deben ser aplicados por un médico con nivel de maestría y acreditado para el ejercicio de la acupuntura. El personal de enfermería deberá proporcionar al paciente tanto autocuidados de algunas de las técnicas (por ejemplo, los implantes auriculares), como colaborar con la aplicación de algunas técnicas, como inserción de agujas, colocación de electrodos en la electroacupuntura, como la moxibustión o ventosas.

Entendida como técnica terapéutica, debe ser contemplada en el marco de la atención medico-sanitaria, con las normas de seguridad y eficacia hacia los ciudadanos que reciben dichos servicios tanto en el sector público. Por ello, consideramos que para la aplicación de la acupuntura debe ser requisito previo el diagnóstico y selección del procedimiento específico de la terapia acupuntural, llevado a cabo por un médico acreditado y competente para ello. Urge definir las competencias y la cualificación del médico que practica acupuntura, así como aquellas delegaciones de funciones en el marco de un proceso asistencial como es el de la acupuntura. Es de hacer notar el aporte que hacen a esto la Organización Médica Colegial, respecto a la capacitación de los médicos acupuntores, con la creación del Visado de Capacitación existente a nivel de los colegios de médicos, y el Documento sobre Ética y Deontología de la práctica de la acupuntura, por el que la Comisión Nacional considera a esta técnica un acto médico.

\section{CONCLUSIONES}

- La acupuntura es un procedimiento médico con bases científicas en continuo crecimiento. 
- Su indicación en determinadas patologías dolorosas es claramente favorable, mientras que en otras aún está por definir.

- Su eficiencia en el tratamiento de la artrosis y del dolor cervical y lumbar crónico ha sido demostrada.

- Por ello, y ante futuras intervenciones en salud pública debería considerarse prioritario potenciar y desarrollar estudios rigurosos de coste-efectividad de la aplicación de la acupuntura en nuestra población.

\section{CORRESPONDENCIA:}

Rafael Cobos Romana

Director científico del Máster de Acupuntura Médica

Universidad Pablo de Olavide. Sevilla

e-mail: rcobos@acmas.com

\section{BIBLIOGRAFÍA}

1. Cobos R, Vas J. Manual de acupuntura y moxibustión. Libro de Texto. Morning Glory Publishers. Beijing. 2000.

2. Li AH, Zhang JM, et al. Human acupuncture points mapped in rats are associated with excitable muscle/skin-nerve complexes with enriched nerve endings. Brain Res 2004;1012(12):154-9.

3. Lee MS, Choi TY, Kang JW, Lee BJ, and Ernst E, Moxibustion for treating pain: A systematic review. Am J Chin Med 2010;38(5):829-38.

4. AHN AC et al. Electrical impedance along connective tissue planes associated with acupuncture meridians. BMC Complementary and Alternative Medicine 2005;5(1):10.

5. AHN AC et al. Electrical impedance of acupuncture meridians: The relevance of subcutaneous collagenous bands. PLoS One 2010;5(7) e11907.

6. Langevin HM, Yandow JA. Relationship of acupuncture points and meridians to connective tissue planes. Anat Rec 2002;269(6):257-65.

7. Shen X, Ding G, Wei J et al. An infrared radiation study of the biophysical characteristics of traditional moxibustion. Complement Ther Med 2006;14(3):213-19.

8. Goldman N, Chen M, Fujita T, Xu Q, Peng W, Liu W et al. Adenosine A1 receptors mediate local anti-nociceptive effects of acupuncture. Nat Neurosci 2010;13:883-8.

9. Goldman $\mathrm{N}$ et al. Purine receptor mediated actin cytoskeleton remodeling of human fibroblasts. Cell Calcium 2013;53(4):297-301.

10. Langevin HM, Churchill DL, Cipolla MJ. Mechanical signaling through connective tissue: A mechanism for the therapeutic effect of acupuncture. FASEB J 2001;15:2275-82.

11. Cobos, R. Aportaciones a la fundamentación neurohistoquímica de la E.A.A.: Localización y modificación del sistema metencefalinérgico en la médula cervical del gato tras estimulación con electroacupuntura. Tesis doctoral. Universidad de Sevilla. 1988.

12. Zhang WT, Jin $Z$ et al. Evidence from brain imaging with fMRI supporting functional specificity of acupoints in humans. Neurosci Lett 2004;354(1):50-3.
13. Chen XH, Han JS. All three types of opioid receptors in the spinal cord are important for $2 / 15 \mathrm{~Hz}$ electroacupuncture analgesia. Eur J Pharmacol 1992;211:203-10.

14. Fei H, Xie GX, Han JS. Low and high frequency electroacupuncture stimulation releases [met 5] enkephalin and dynorphin A and B in rat spinal cord. Chin Sci Bull 1987;32:1496501.

15. Chen XH, Guo SF, Chang CG, Han JS. Optimal conditions for eliciting maximal electroacupuncture analgesia with dense-and-disperse mode of stimulation. Am J Acupunct 1994;22:47-53.

16. Han JS. Acupuncture: Neuropeptide release produced by electrical stimulation of different frequencies. Trends Neurosci 2003;26(1):17-22.

17. Han JS, Chen XH, Sun SL, Xu XJ, Yuan Y, Yan SC, et al. Effect of low- and high-frequency TENS on met-enkephalin-Arg-Phe and dynorphin A immunoreactivity in human lumbar CSF. Pain 1991;47:295-8.

18. Guo HF, Fang Y, Wang XM, Han JS. Brain substrates activated by electroacupuncture (EA) of different frequencies. II: role of fos/jun proteins in EA-induced transcription of preproenkephalin and preprodynorphin genes. Brain Res. Mol. Brain Res. 1996;43:167-73.

19. Han JS, Xie GX, Zhou ZF, Folkesson R, Terenius L. Enkephalin and b-endorphin as mediators of electroacupuncture analgesia in rabbits: An antiserum microinjection study. Adv Biochem Pharmacol 1982;33:369-77.

20. Han JS, Li SJ, Tang, J. Tolerance to acupuncture and its cross tolerance to morphine. Neuropharmacology 1981;20:593-6.

21. Stux, G. y Pomeranz, B. Fundamentos de acupuntura. Masson (Elsevier); 2004

22. Le Bars D, Gozariu M, Cadden SW. Animal models of nociception. Pharmacol Rev 2001;53(4):597-652.

23. Vas $J$ et al. Acupuncture as a complementary therapy to the pharmacological treatment of osteoarthritis of the knee: Randomised controlled trial. BMJ 2004; 329(7476):1216.

24. Whitehurst, DT, et al. Cost-effectiveness of acupuncture care as an adjunct to exercise-based physical therapy for osteoarthritis of the knee. Physical therapy 2011;91(5):630-41.

25. Reinhold T, Witt CM, Jena S, Brinkhaus B, Willich SN. Quality of life and cost- effectiveness of acupuncture treatment in patients with osteoarthritis pain. Eur J Health Econ 2008;9:209-19.

26. Willich SN, Reinhold T, Selim D, Jena S, Brinkhaus B, Witt CM. Cost- effectiveness of acupuncture treatment in patients with chronic neck pain. Pain 2006;125:107-13.

27. Haake M, Muller H, Schade-Brittinger C, Basler HD, Schafer $\mathrm{H}$ et al. German Acupuncture Trials (GERAC) for chronic low back pain. Arch Intern Med 2007;167(17):1892-8.

28. Yuan, $\mathrm{J}$ et al. Effectiveness of acupuncture for low back pain: A systematic review. Spine 2008;33(23):E887-E900.

29. Witt CM, Jena S, Selim D, Witt CM, Jena S, Selim D, Brinkhaus B, Reinhold T, Wruck K et al. Pragmatic randomized trial evaluating the clinical and economic effectiveness of acupuncture for chronic low back pain. Am J Epidemiol 2006;164:487-96.

30. Ghoname EA et al. Percutaneous electrical nerve stimulation for low back pain: A randomized crossover study. Journal of the American Medical Association 1999;281(9):81823.

31. Lund I, Lundeberg T, Lonnberg L, Svensson E. Decrease of pregnant women's pelvic pain after acupuncture: A randomized controlled single-blind study. Acta Obstet Gynecol Scand 2006;85(1):12-9. 
32. Itoh K, Katsumi Y, Kitakoji H. Trigger point acupuncture treatment of chronic low back pain in elderly patients - a blinded RCT. Acupunct Med 2004;22(4):170-7.

33. Accesible en: NICE Low back pain (early management): Overview http://pathways.nice.org.uk/pathways/ low-back-pain-early-management.

34. Diener HC, Kronfeld K, Boewing G, et al. Efficacy of acupuncture for the prophylaxis of migraine: A multicentre randomized controlled clinical trial. Lancet Neurology 2006;5(4):310-6.

35. Endres HG, Diener HC, Molsberger et al. Role of acupuncture in the treatment of migraine. Expert Review of Neurotherapeutics 2007;7(9):1121-34.

36. Coeytaux RR, Kaufman JS, Kaptchuk TJ et al. A randomized, controlled trial of acupuncture for chronic daily headache. Headache 2005;45(9):1113-23.
37. Melchart D, Streng A, Hoppe A et al. Acupuncture in patients with tension-type headache: Randomized controlled trial. BMJ 2005;331:376-82.

38. Accesible en: NICE Management of headache: http:// pathways.nice.org.uk/pathways/headaches\#path=view\%3A/ pathways/headaches/management-of-headaches.xml\&content $=$ close.

39. Vickers AJ et al. Acupuncture for chronic pain: Individual patient data meta-analysis. Arch Intern Med 2012;172(19):1444-53.

40. Lao L, Hamilton GR, Fu J et al. Is acupuncture safe? A systematic review of case reports. Altern Ther Health Med 2003;9(1):72-83. 